\title{
Three perspectives on relational values of nature
}

\author{
Sanna Stålhammar ${ }^{1}\left[\right.$ Henrik Thorén ${ }^{1,2}$
}

Received: 11 August 2018 / Accepted: 12 July 2019 / Published online: 27 July 2019

(c) The Author(s) 2019

\begin{abstract}
Relational value (RV) has recently been introduced as a third class of values for understanding values of nature and are thought to sit alongside more familiar axiological categories such as instrumental and intrinsic value. The concept has quickly gained ground in and promises to better capture how people and collectives perceive of their wellbeing and make choices that involve the natural world. While the idea of relational value is not without merits, its initial and current conceptualization raises questions about how it relates to existing value concepts. Here, we start from an interdisciplinary perspective and delineate how the concept can contribute to addressing problems in three fields that deal with environmental values in different ways: environmental ethics; ecosystem services valuation; and environmental psychology. We provide an overview of value concepts in each field and show how relational value has been described or applied. Our analysis shows that value concepts are used to solve different problems in the three fields, and these differences have implications for how relational value can be framed and situated in values theory. These differences involve e.g., the descriptive question of how people value nature versus the normative questions of why nature should be valued. We show how the concept can be seen as solving the problem of narrow conceptualizations of intrinsic and instrumental value in ecosystem services valuation and suggest that RV can be conceived of as an epistemological framing rather than a values concept. The concept also has potential to function as a 'boundary object' to provide cross-fertilization of disciplinary perspectives.
\end{abstract}

Keywords Relational value $\cdot$ Intrinsic value $\cdot$ Environmental values $\cdot$ Environmental valuation $\cdot$ Socio-cultural valuation . Ecosystem services value

\section{Introduction}

A wave of "relationality" has recently swept the scholarly discussions on ecosystem services (ES) (e.g., Chan et al. 2016; Arias-Arévalo et al. 2017, 2018; Díaz et al. 2015). Proposed as a "third class of values" (Chan et al. 2016, p. 1462) for understanding values of nature, relational values (RVs) are intended to sit alongside the axiological

Handled by Jasper O Kenter, University of York, United Kingdom.

Sanna Stålhammar

sanna.stalhammar@lucsus.lu.se

Henrik Thorén

henrik.thoren@fil.lu.se

1 Lund University Centre for Sustainability Studies, Lund University, Lund, Sweden

2 Helsinki Institute of Sustainability Science, University of Helsinki, Helsinki, Finland categories of instrumental and intrinsic value. The concept is thought to better capture how people and collectives perceive of their wellbeing and make choices that involve the environment; including "preferences, principles, and virtues associated with relationships both interpersonal and as articulated by policies and social norms" (Chan et al. 2016, p. 1462). Proponents of the concept have voiced hope that the concept can help overcome long-standing intellectual conflicts regarding the value of nature, and provide a conceptual basis flexible enough to encompass the plurality of values and worldviews necessary for the ES framework to do its job (Jax et al. 2013; Himes and Muraca 2018). In spite of the rise in popularity of the concept being rather recent, the influence has been significant. The International Panel on Biodiversity and Ecosystem Services (IPBES) framework for understanding nature's contributions to people (Díaz et al. 2018; Pascual et al. 2017) has incorporated the values category and the British Ecological Society recently launched their sixth journal 
People and Nature under the slogan "a journal of relational thinking".

In a recent special issue devoted to RV (Pascual et al. 2018), Chan et al. (2018) explained the development of the concept as a strategic aspiration of bridging ideas across fields to affect the discourse on values in science-policy organizations, as well as relying on a tactical opportunity tied to the word 'values' in the IPBES conceptual framework. As the authors note, however, this use of RV as a value category raises familiar conceptual concerns, and they state that "there is a real danger that an ambiguous term is popular because everyone sees what they want in it, but there is no common ground for collective action or insight." (Chan et al. 2018, p. A2). The development of the concept has multiple aims and is considered to address multiple interdisciplinary problems related to sustainability, but it is unclear to what extent the framing as a values concept is appropriate to contribute to these goals.

Recent efforts have provided valuable clarifications on the theoretical foundations of RV and how to fit the concept in its historical and philosophical context (Pascual et al. 2018). RV has also been compared to other value categories such as assigned, held, and moral values (Chan et al. 2018), and Himes and Muraca (2018) provided the definition of RV as anthropocentric yet non-instrumental. However, questions remain as to how the notion of RV connects, and informs, entrenched ways of thinking about values. Piccolo (2017) pointed out that the conceptualization is departing from a too simplistic construal of conventional philosophical distinctions, such as that between intrinsic and instrumental values. As RV takes on a life of its own in academic and policy contexts, it is important to understand its theoretical underpinnings and rationales, in particular since different fields may have contrasting views of value as a concept (see Kenter et al. 2019; Rawluk et al. 2019 this issue).

With this paper, we aim to contribute to an understanding of the RV concept as a theoretical construct taking an interdisciplinary perspective. The objective is to critically examine, where and how the concept can contribute to our understanding of values within different disciplinary contexts. Starting from the perspective of RV as advocated by Chan et al. $(2016,2018)$ we delineate what 'job' the concept is described to do through comparing it to existing value concepts in three fields that deal with environmental values and value concepts in different ways: environmental ethics, ecosystem services valuation, and environmental psychology. We use three guiding questions to frame our analysis of each field: How are value concepts defined in the field? How has relational value been described or applied with reference to these value concepts? What perspectives can relational value add?

\section{Relational value across three fields}

The present focus on RV as an explicit concept in the intellectual discourse on ecosystem services is quite recent and has risen to prominence only in the past half a decade or so (Muraca 2011; Jax et al. 2013; Díaz et al. 2015; Chan et al. 2016; Pascual et al. 2017, 2018). Notably, the concept is used in more than one sense in the literature and can highlight different points depending on the chosen definition. For example, while most accounts align with Chan et al. (2016) who refer to social conditions and perceptions, Arias-Arévalo et al. $(2017,2018)$ describe how RV also includes ecological conditions ensuring the preservation of life on earth. Chan et al. (2018) describe how the development of the concept has been mainly motivated by interdisciplinary inclusion and real-world application and is argued to better capture how people actually think of and value nature (Chan et al. 2016).

In Chan et al. (2016), at least three claims can be identified with regards to what constitutes RV, which we have aligned with value concepts in three fields. These three fields are environmental ethics, ecosystem services valuation, and environmental psychology, and they align with the three claims in the following manner: (1) RV is stated as a third value class next to the ethical value categories of intrinsic and instrumental value (see e.g., Himes and Muraca 2018); (2) RV is explicitly described as a way to overcome challenges in cultural ES valuation; and (3) RV is described as a better way of framing how people behave and are motivated in relation to the environment which is, not limited to, but encompassed by environmental psychology (Chan et al. 2016). The focus on environmental psychology here is not exhaustive of the third claim, and we recognize that many other fields and disciplines are relevant. Yet, environmental psychology employs values concepts with distinct methodologies for values constructs (Schultz 2001; Stern and Dietz 1994) building on Schwartz theory of basic values (Schwartz and Bilsky 1987; Schwartz 2012). This can be contrasted to e.g., anthropology and human geography, which use a wide variety of mostly qualitative approaches to identify context-specific value relationships (Ives and Kendall 2014).

We treat the three perspectives of environmental ethics, (cultural) ES valuation, and environmental psychology as idealized approaches to value conceptualization and analyze how RV is contributing to solving problems within each field. Importantly, there are diverse ontological and epistemological starting points (and associated assumptions) for understanding both values and relations within a discipline or field and we do not aim to provide an overview of all possible ways that these concepts could be 
interpreted in the three fields. Moreover, the concept of relations does not equal RVs and instead of examining relations more broadly we wish to incite a deeper theoretical engagement with RV by providing a brief overview of values concepts and categories specifically, as well as a few interpretations of RV from within the fields. We will now turn to outlining what the concept of value means in each of these three fields and related framings of RV.

\section{Value in environmental ethics}

Ethics - or sometimes moral philosophy—is a branch of philosophy that can be understood as the "systematic endeavour to understand moral concepts and justify moral principles and theories" (Pojman 2012, 4). Ethics is divided into three main sub-fields; normative ethics, meta-ethics, and finally applied ethics, which environmental ethics sorts under. Applied ethics is concerned with the morality of specific choices such as e.g., abortion, euthanasia, or gene therapy. Environmental ethics is the philosophical study of the normative underpinnings that guide how humans should behave towards nature.

Environmental ethics as a field grew out of the environmental crisis of the 1960s and the broader concerns with the negative human influence on the natural environment and worries about the consequences of unmitigated growth voiced in a number of widely influential works e.g., Carson (1962), Ehrlich (1968), White (1967), Boulding (1966), Har$\operatorname{din}(1968){ }^{1}$

With respect to value concepts, the operative distinction has often been between intrinsic and instrumental values: typically understood as that which is valuable as an end in itself versus that which is valuable as a means to an end. A fundamental question has been whether nature (or some part of nature) is to be valued for its own sake, or whether it is "merely" instrumentally valuable. ${ }^{2}$ Here, environmental ethicists, such as Arne Næss, often reacted against what they perceived to be a narrow anthropocentric position and sought to replace it with a more permissive ecocentric view, lending moral status to various other entities (see Brennan and Lo 2016; O'Neill et al. 2008). Næss was an influential

\footnotetext{
1 Although it is conventional to think of the field as originating during this time there were important predecessors. In particular Aldo Leopold, and his essay Land Ethic in A Sand Country Almanac (Leopold 1949), but also George Perkins Marsh's Man and Nature (1864) and Alexander von Humboldt's Views of Nature (von Humboldt 1850). See Brennan and Lo (2016) and Kawall (2017) for more thorough historical introductions to the environmental ethics.

${ }^{2}$ It is common to assume that the distinction between instrumental and intrinsic value involves a commitment to the idea of the latter being immeasurably greater than the former (see e.g. Justus et al. 2009). But to the contrary, it is possible, as Schmidtz (2015) points out, to make trade-offs between intrinsic and instrumental values.
}

figure in the 1970s and fathered the Deep Ecology Movement as well as a kind of philosophy of ecological harmony he termed Ecosophy. He argued for what he called biospherical egalitarianism suggesting that all living things are intrinsically valuable (see Næss 1973).

However, the intrinsic/instrumental distinction is complex. As O'Neill et al. emphasize (2008, p. 114; see also O'Neill 1992; O'Connor and Kenter 2018, this issue) the term 'intrinsic value' has more than one meaning. Three varieties can be distinguished:

1. Intrinsic value as non-instrumental value

2. Intrinsic value as valuable in virtue of its intrinsic properties

3. Intrinsic value as objective value

The first interpretation is perhaps the most common. Noninstrumental value is typically understood as pertaining to Kantian ends-in-themselves, paradigmatically exemplified by other humans to whom we owe moral responsibilities. The second version of the concept is often associated with Moore (1922) and relates intrinsic value to intrinsic properties. Intrinsic properties are understood to be non-relational properties; i.e., properties that objects have, not in virtue of some relation that stand in respect to some other object. Precisely what this means is not self-evident but O'Neill (1992) offers rarity as a paradigmatic example of a relational property. A non-relational property of an object might be e.g., it being sentient. The third variety associates intrinsic value with objective value; that is value that is independent of the evaluative attitudes of some subject. O'Neill further distinguishes between a weak and a strong interpretation of objectivity. On what O'Neill labels the weak interpretation intrinsic value is a property that an object may have even in the absence of some valuing subject. The strong interpretation, on the other hand construes objectivity rather in terms of whether it is possible to characterize evaluative properties "without reference to evaluating agents" (O'Neill 1992, 126). For instance, sentences such as "moist and welldrained soil, rich in organic matter are good for rhododendrons" seems to make no reference to evaluating agents. In what follows we will mainly concern ourselves with the weak interpretation.

While commonly conflated and subject to equivocation, the three interpretations of intrinsic value are independent. For example, consider the meta-ethical distinction between objectivism and subjectivism with respect to values. The objectivist thinks that intrinsic values exist even in the absence of evaluative attitudes of some valuing subject. On this take it is natural to interpret intrinsic value according to O'Neill's third construal, which is as objectively existing. The subjectivist, on the other hand, claims that all values emanate from the evaluative attitudes of some subject, 
crucially even intrinsic values. In this understanding, $\mathrm{X}$ is intrinsically valuable if and only if some subject holds $\mathrm{X}$ to be valuable for its own sake. This is compatible with O'Neill's first construal. An environmental ethicist should find it difficult to be objectivist about values and at the same time embrace anthropocentrism: the former view would involve saying that nature is valuable even in the absence of a valuer, whereas the latter position either extends moral status only to humans or at least strongly emphasizes humans as moral agents.

\section{Relational value and environmental ethics}

The term 'relational value' is not part of the standard nomenclature of environmental ethics. Influential works, such as e.g., O'Neill et al. (2008), make no mention of the term, and some philosophers have been markedly suspicious of its recent rise (see e.g., Maier and Feest 2016; Piccolo 2017). That is not to suggest that environmental ethicists are not interested in relations or relationships with respect to values. Quite to the contrary, the role of relations, not least evaluative relations are prevalent and important in how central distinctions can be understood. Before we return to this, let us make a couple of observations with respect to the recent relational values literature.

A point of terminology. The terms'relation' and 'relationships' are not necessarily synonymous. One suspects that the notion of 'relationship' already tends to be more imbued with values at the outset than 'relations'. In this paper, however, we will use these terms interchangeably and commit ourselves to nothing more than the most plain understanding of what a relation might entail.

One can discern two ideas that appear to be common in this literature. First, the notion of RV can be used to say something about what is of value. Chan et al. (2016, p. 1462) note that "relational values are not present in things but derivative of relationships and responsibilities to them." By distinguishing between "the innate relationality of all evaluative process and relational value as the content of valuation", Himes and Muraca (2018, p. 1) describe RV as concerned with relations being the objects of value. Chan et al. (2018, p. E4) follow their distinction and describe RVs as: "values where the relationship itself matters, as more than a means to an end (a preference for seeing birds is relational in origin; a sense of kinship with birds is relational in content)". Part of this idea is that relations not only hold certain values but also that values arise out of these relations.

The second idea targets not the objects of value, but the sharp distinction between a valued object and a valuing subject. That is to say, a commitment to a sharp humannature distinction fundamentally obscures how humans are ultimately part of nature. Such ideas have been suggested by philosophers, such as Muraca (2011), but can be traced also in e.g., Chan et al. (2016), for instance in their assertion that some indigenous people tie their identity to the natural environment and would find it difficult to think of themselves as separate from it in the first place (see Gould et al. 2019; Ingold 2006; O'Connor and Kenter 2018).

Returning to environmental ethics, both of these points have been important themes in the field. A philosopher might point out that Chan et al. (2016) make it easy for themselves by committing to a narrow understanding of the intrinsic/instrumental distinction. For example, they write "Consider a tree or grove deemed sacred, associated with collective histories, ancestors, or sustenance of many kinds. Is it valuable intrinsically (independent of human valuation) or instrumentally (for preference satisfaction)?" (Chan et al. 2016, p. 1463). Here, intrinsic values are thought of as objective values, but they are contrasted against preference satisfaction. This particular way of construing the intrinsic/instrumental distinction is not necessarily exhaustive in the relevant domain and if it is the only distinction one has to elaborate with then clearly the choice is limiting. Most philosophers, however, operate with a very nuanced understanding of these concepts, and in particular a more fluid way of deploying them that appear not to preclude the points that Chan and colleagues are calling for (see Piccolo 2017). Another difference, whereas philosophers often construe the instrumental/intrinsic distinction such as to exhaust the domain - e.g., by defining one concept in the dichotomy as the negation of the other (usually in service of some other point)—Chan and colleagues make no such commitment. A questioning of the human/nature distinction has also long been part of environmental ethics. Arne Næss, for example, was explicit in arguing for a "relational, total-field image" to replace the otherwise prevalent "man-in-environment image" (Næss 1973, 95). The point here is not that Chan and colleagues are mistaken, but that they use concepts and definitions in a different manner.

The most detailed philosophical treatment of RVs is due to Muraca (2011) and Himes and Muraca (2018) whose work has been a strong influence on proponents of the concepts (Chan et al. 2016; Díaz et al. 2015; Chan et al. 2018). Muraca departs, to an extent, from the conventional intrinsic/instrumental distinction and contrasts intrinsic values (thought of as Kantian as-ends-in-themselves) with relational and instrumental values. Himes and Muraca (2018) argue for the reservation of the term 'intrinsic values' to "the attribution of inherent moral value to entities that can be legitimately considered as subjects-of-a-life or ends in themselves in a moral sense" and define RVs as "non-instrumental anthropocentric' values (p. 3). An important motivation for Himes and Muraca is the narrowness of the intrinsic/instrumental distinction, and this focus to a degree simply bypasses some entrenched problems in environmental ethics such as the subjectivist/objectivist dispute. 
The ambition of Chan et al., however, appear to be pragmatic when they suggest that it does not matter that the intrinsic/instrumental framework can be expanded to include relational values if it cannot be used to communicate with relevant groups and stakeholders. Similarly, Himes and Muraca (2018) refer to RVs as a new category of value assessment, i.e.: "a new and fruitful category for expressing the importance of specific relationships people hold with non-human nature" (p. 1). The idea here is that the axiological framework that is needed has to be judged not on its philosophical merits alone, but also in how well captures and resonates with how relevant agents actually make valuebased decisions. In this sense, Chan et al. depart in their aims from those that environmental ethics typically targets. Conventionally environmental ethics deals with the normative question of how and why we should value nature per se. The concern with intrinsic values in environmental ethics stems from ideas about how we should value nature; e.g., nature should be valued as an end in itself and not merely a means to end (Kawall 2017). Environmental valuation, on the other hand, tries to establish, how, why, and the extent to which, some group or community values nature. This project is in an important way descriptive in that, although there may be normative assumptions behind the valuation approach taken, valuation tries to describe values rather than answer what values we should have with regard to nature.

\section{Value in ecosystem services valuation}

The goal of environmental valuation is to produce scientifically informed assessments of natural resources to provide a rational basis for decision-making (Shmelev 2012). This logic and method have received increased attention and importance with the international policy agenda that has called to value and assess ES at local, regional and national levels (MEA 2005; TEEB 2010).

ES valuation is not a comprehensive field but is made up of various disciplinary and interdisciplinary research efforts, which span the natural and social sciences (in particular economics), and aim to assess the value of ES in either quantitative or qualitative terms (Maes et al. 2016). Since the emergence of the concept, the valuation methods, as well as their usefulness for decision-making, have been subject to discussion (Costanza et al. 2014; de Groot et al. 2010, 2012; Daily et al. 2009; Silvertown 2015). ES valuation encompasses methodology from both mainstream environmental economics and ecological economics, which draw on different starting points for understanding dynamics between biosphere and economy (Venkatachalam 2007). While many of the methods that were initially applied and proposed for ES valuation had a narrow focus on ecology and economics (TEEB 2010), the research paradigm has more recently broadened to include diverse epistemologies and methodologies (Braat Leon 2018).

ES valuation can be seen as operating with a tripartite typology of values differing between ecological, economic, and social value domains. These artificial categories are a pragmatic way of allowing for the multiple involved disciplines to focus on values in proximity to their respective area (Kronenberg and Andersson 2019, this issue). The idea of ecological values moves ES valuation beyond strictly economic analysis. This notion, that there are ecological values pertaining to the life-support system of the ecosystems upon which we depend, is a foundational idea in ecological economics and a point of departure for the ES concept (Erlich and Mooney 1983). Social values have recently received more attention, even though the idea is not new in ecological economics (Kenter et al. 2015). Social values have been defined in a variety of ways (Kenter et al. 2015) but can be described as those values that people express regarding the environment that are neither strictly ecological nor necessarily captured in meaningful ways by monetary metrics. Social values, like many of those values encompassed by ES valuation methods, are subjective values in a methodological sense, in that they build on social perceptions of environments (Hejnowicz and Rudd 2017). Typical examples are emotional, affective, spiritual and symbolic values (GómezBaggethun and Martín-López 2015). These values were in the literature initially associated with cultural ES, but have more recently been recognized to be considerably broader and not limited to 'non-material' benefits, since most ES have social and cultural dimensions (Kenter 2016; Scholte et al. 2015; Kirchhoff 2012). The valuation methods used are varied with regards to disciplinary and methodological approaches, with the uniting aim to rank values towards ES in non-monetary terms (see Gómez-Baggethun and Martín-López, 2015, Table 11.1). Application of sociocultural valuation of ES in Europe has been shown to mainly been intended for 'awareness raising', i.e. establishing and communicating knowledge of values and preferences that stakeholders and citizens hold and assign to ES for decisionmaking (Walz et al. 2019).

The fundamental concept of value has been defined and applied with various different meanings in the ES literature (Hejnowicz and Rudd 2017). In the cultural ES literature, value is usually taken to mean "evaluative beliefs about the worth, importance, or usefulness of something or about moral principles" (Hirons et al., 2016, p. 556). While few applications of valuation define value concepts more explicitly, Kenter et al. (2015) provide a definition of value concepts for ES valuation building on the distinctions between transcendental and contextual values as well as value indicators (see "Value in environmental psychology").

The role of intrinsic values is a point of contention within ES valuation. The ES framework builds on an 
anthropocentric perspective that only considers functions of ecosystems that are of use in meeting human needs or desires. ES valuation is further seen as encompassing only instrumental values. It is unclear to what extent intrinsic value can be appropriately captured by ES valuation approaches (Scholte et al. 2016; Hirons et al. 2016) and as demonstrated by O'Connor and Kenter (2018, this issue) this in part depends on what is meant by intrinsic value. Intrinsic value is frequently understood as weak objective value, that is, as value that an object has even in the absence of some valuing subject (see "Value in environmental ethics"), and on those terms is excluded from valuation. As we will see in the next section, relational value then helps to solve the problem of this narrow scope of intrinsic value in ES valuation by broadening what types of values can be included in valuation.

\section{Relational value in valuation of ecosystem services}

As a trending concept in the ES literature, RV has already been adopted in socio-cultural valuation studies. Small et al. (2017) describe how the environmental valuation category of socio-cultural values can be further divided into three value domains: instrumental, intrinsic, and relational value, following the value typology outlined by Chan et al. (2016). Klain et al. (2017) call for the development of more qualitative approaches since they describe how the qualitative foundations of cultural values which are essential for well-being, including connectedness and belonging to a community, are not encompassed by quantitative assessments. Other scholars argue that instrumental values, in the form of monetary and non-monetary preferences, do not fully capture the ways that people assign worth to nature in practice, and overlooks significant meanings and ethical questions of human-nonhuman relations (Jax et al. 2013; Chan et al. 2012, 2016). Consequently, RV is proposed as a third category to get around the methodological problem of preference-based operationalization of value vis-à-vis intrinsic value as separate from humans.

To some extent, RV draws on Brown's (1984) conceptualization of values as related to economic preferences. Brown described held values as influencing RVs, which are implicit preference judgments sometimes not available to elicitation, which in turn influence an expression of a preference, i.e. an assigned value (Brown 1984, p. 233). An important difference between the ideas is that RVs are considered subject to elicitation in e.g., CES valuation, as they can be equated with 'assigned values' (Chan et al. 2018). Schroeder (2013, p. 78) also builds on Brown's idea of RV but rejects the linear focus on preferences and suggests instead that RVs (or what he refers to as "felt values') underlie and are more fundamental than both held and assigned values. This description somewhat resonates with RVs, even though RV is not necessarily described as more fundamental. Felt values are seen as more immediate, affective and experiential and require a shift from the cognitive and analytical view of value to a perspective that recognizes the process of making decisions (Schroeder 2013, p. 77). This idea of context-specific and underlying emotional RVs is closely related to the idea of the importance of meanings of environments, often highlighted by the concept's proponents (i.e. Chan et al. 2016).

The inclusion of meaning through RV seems to be precisely how the concept is intended to contribute to sociocultural valuation. The framing of value in socio-cultural valuation has been described as a poor fit with how people actually think or behave, which proponents argue is better described with the framing of relational value (Chan et al. 2016). Tadaki et al. (2017) suggest that RV challenges and exceeds instrumental and intrinsic value and changes the premise for valuation from preferences to including what different ecosystems 'mean' to people. Using meanings to understand the importance (or 'value') of people's relations with environments for their wellbeing is new to the field of environmental valuation, and requires methodological changes to be accounted for. To Tadaki et al. (2017), the value-as-relations concept emphasizes two things, namely: it involves more open-ended conversations about how and why environments matter to people, including a thoroughly place-based perspective; and it positions economic theories of value as merely "one type of relationship among many". In practice, the applications of the RV concept is stated to seek qualitative richness using openended methods such as interviews and discourse analysis, drawing on approaches from anthropology, environmental sociology, geography, history and cultural studies (ibid.). In other words, RV involves an engagement with more constructivist epistemologies and perspectives on how to conceive of human-nature relations, where meanings are seen as contextual and place-based. However, such engagement has, to some extent, already been described within the ES valuation scholarship, without reference to the relational values concept per se. For example, Fish et al. (2016) conceptualize cultural ES based on a 'relational approach', which does not suggest new categories of value but instead advances the analytical and empirical categories of ES based on a constructivist approach. The special issue on 'shared, plural and cultural values' (Kenter 2016) also includes various examples of qualitative and humanities-based approaches for understanding value. This points to the direction that relational value can be seen as a widening of epistemological perspectives in ES valuation rather than filling a gap for a new values concept. Similar ideas, of value not being constituted by preferences and the rejection of methodological individualism, have been formulated in ecological economics and 


\begin{abstract}
(1) stimulation theories, which focus on the physical environment as a source of sensory information; (2) control theories that emphasize the importance of an individual's real, perceived, or desired control over stimulation; (3) ecological psychology which takes a dynamic-system approach to person-environment relations; (4) integral approaches such as organismic theory that strive to comprehensively describe the complex interrelationship of persons and settings; (5) operant approaches, which employ behavior modification techniques; (6) environment-centered theories, e.g. ecopsychology, which emphasize the environment's own welfare; and (7) theories that include elements such as goals, norms, intentions, values, and attitudes (Gifford 2014).
\end{abstract}

Box 1 Major theoretical approaches in environmental psychology

predates the idea of relational values (see Kenter et al. 2015; Sagoff 1994).

A central argument for RV is its claim to describe how people actually think or behave better than the value conceptualizations that are currently dominating environmental valuation and policy (Chan et al. 2016). The goal of environmental valuation has been to produce more accurate ways of assessing the value of ecosystems. Only recently has this come to include the idea of more accurately describing people's inner worlds. How people value, think and behave in relation to the natural environment is the focus of environmental psychology, which we shall now turn to.

\section{Value in environmental psychology}

Environmental psychology is an interdisciplinary field of study concerned with the interrelationships between people and their surroundings. Such interrelationships include the physical surroundings, both the built and natural environment, the use of natural resources as and pro-environmental behavior. The field can be divided into at least eight major theoretical approaches (see Box 1). The descriptive-empirical knowledge field of environmental psychology is one of the main areas of study for understanding the relationship between wellbeing and natural environments.

In environmental psychology, theories and studies on values are largely based on the work of Rokeach (1973) and Schwartz (1992). A value is defined as "a desirable transsituational goal varying in importance, which serves as a guiding principle in the life of a person or other social entity" (Schwartz 1992, p. 21). Values in this meaning are also referred to as 'held' values, since they are seen as cognitive elements that are deeply held, and are considered relatively stable throughout adult life. They are seen as foundational for other forms of cognition such as attitudes, norms and behavioral intentions (Fulton et al., 1996) and are considered important to study since they play a significant role in explaining specific beliefs and behavior (Stern 2000).

Whereas ethicists debate the meaning of categories of value such as instrumental and intrinsic, environmental psychology has drawn upon these categories to conceptualize different value orientations that people have. Three value orientations (clusters of values) have been posited as relevant to environmentalism, namely the egoistic, social-altruistic, and biospheric (Stern et al. 1993). ${ }^{3}$ Biospheric values are conceptualized based on writings around the philosophical idea of 'deep ecology' from Devall (1988) and Næss (1989), which includes ascribing intrinsic value to living entities and ecosystems. The idea is that the different value orientations can influence attitudes of environmental concern which then can influence different pro-environmental behaviours (Stern and Dietz 1994). Even though psychological values are explained as associated with ethics, normative beliefs, and guiding principles, these values categories are psychological conceptualizations where values are viewed as cognitive representations and are not axiological or philosophical value categories.

The value concept in psychology has explicitly been connected to valuation of ES (Raymond and Kenter 2016). Here, psychological values are referred to as transcendental values. Within the field of socio-cultural valuation, an important recent distinction is made between transcendental, contextual values and value indicators. Transcendental values concern "guiding principles that transcend specific situations", which are based on the psychological concept of values, whereas contextual values are "opinions about worth or importance, which are dependent on an object of value" (Kenter et al. 2015, p. 89). As Kenter et al. (2015) point out,

\footnotetext{
${ }^{3}$ Egoistic values represent self-interest; social-altruism represents altruism towards other humans; and biospheric values represent altruism towards other species and the biosphere.
} 
the distinction between transcendental and contextual values bears resemblance to the distinction between 'held' and 'assigned' values described above, but transcendental and contextual values are considered more refined with regards to conceptualizing specifically how the worth of an object is deemed a contextual value. Various other theories and instruments have been employed to connect environmental psychology to the idea of ES such as: value orientations (Hicks et al. 2015), place identity and naturalness (Knez et al. 2018), wellbeing indexes (Bryce et al. 2016), and in relation to monetary valuation (Raymond and Kenter 2016; Kenter et al. 2016). However, not all of these approaches employ the term 'value'.

\section{Relational value and environmental psychology}

How relationality at large could be interpreted in the field of environmental psychology is beyond the scope of this paper, and we are here concerned with how RV can be interpreted and compared with existing value concepts. It is uncertain how RV correlates with psychological values, since these can be described as 'held values', i.e., cognitive and deeply held elements. Chan et al. (2018) clarify that they see RVs as different from held values, since held values are abstract and $\mathrm{RVs}$ are considered to be grounded in particular contexts. The concept of values in psychology, as well as e.g., transcendental values, is then supposedly not compatible with RVs at all. On the other hand, RV has been described as related to held values since moral duties can determine how individuals relate with nature (Díaz et al. 2015).

Moreover, there is some confusion regarding how RV should be considered with regards to the characteristics of abstractness and context (Rawluk et al. 2019, this issue). Chan et al. (2018) describe RVs as context-dependent, and Rawluk et al. characterize RVs as not subject to generalization. In contrast, Schulz and Martin-Ortega (2018) argue for the use of quantitative approaches to identify universal RVs shared across cultures, and state that theoretical constructs in environmental psychology such as worldviews, values, and beliefs could be understood as elements of relational values. Such application thus ignores context dependence and employs held values as elements of RVs. Klain et al. (2017) follow this approach to employ the idea of RV to see how it compares to a method to measure beliefs about nature; the New Ecological Paradigm (NEP) scale. Beliefs are considered closely related to values, but whereas values are seen as more foundational and stable guiding principles, beliefs constitute the inner core of a person's worldview and 'basic truths' about the physical and social reality (Dunlap et al., 2000). Klain et al. (2017) complement the NEP scale by adding 'relational value statements' and found these responses as distinct from
NEP statements, interpreted as having potential as forming a new index. They point out that what RV is describing is not new conceptual territory in environmental psychology and instead refer to it as a 'framing'. RV, or a relational framing, is here considered to help solve a methodological problem of how to better understand the relationship between how different value framings ultimately influences behavior by adding more variables (Klain et al. 2017, Fig. 4). This operationalization of RV does not imply an engagement with qualitative or constructivist methodology, or a deeper engagement with 'meanings' as suggested in the socio-cultural valuation section above.

Application of RV in environmental psychology also raises questions regarding how the level of engagement with the ontological underpinnings of RV (i.e. Muraca 2011) should be interpreted by different fields. Operationalizing RV as an additional variable does not necessarily account for the ontological ideas of relationality that proponents argue is important depending on how that relationality is interpreted. If RV is to be interpreted as operationalized based on the metaphysical meaning of the term, i.e. according to a non-dualist 'radical relationality' (Muraca 2016), then an engagement with the underlying ontological perspective of environmental psychological approaches is required, such as the difference between interactional and transactional worldviews (Altman and Rogoff 1991). The theories related to value outlined above in environmental psychology builds on an interactionist perspective, which sees sharp distinctions between the outside 'objective' world and the inside 'subjective' world (see Fodor 1997). More relational, or non-dichotomous perspectives can be interpreted as those building on a transactional worldview where the dynamic unity and mutually defining aspects between people and setting is emphasized (Werner and Altman 2000).How relational value should be interpreted with regards to underlying epistemological (and ontological) perspectives is thus important to consider and would imply different outcomes for its operationalization.

Moreover, there are various approaches in environmental psychology that could be interpreted as describing or studying the content of RV in some aspects, but that do not employ psychological values concepts. For example the Nature Connectedness scale (Mayer and Frantz 2004) measures individual's feeling of community with nature, and the inclusion of Nature in Self scale (Martin and Czellar 2016) assesses individual environmental identity. The concept of place-attachment (Altman and Low 1992), i.e. the emotional bond between person and place, is also a way of interpreting how RV could be conceptualized with its strong focus on contexts and experiences for understanding meanings of places. 


\section{Discussion}

We have investigated how the notion of RV fits within three fields through outlining their respective value taxonomies and conceptualizations. We have shown how value concepts within these fields are used to serve different aims and address different questions. Most obviously there is a tension between the fundamental normative questions (primarily targeted in environmental ethics), and descriptive questions concerning how people value and behave with regards to nature (concerns of ecosystem services valuation and environmental psychology) Nonetheless, the idea of RV is a potentially fruitful way to broaden perspectives on values in general and may prove to its worth as an epistemological framing in ES valuation, but as a value category it is not entirely convincing. We see a few potential risks associated with the use of the concept, but also its potential as a boundary object and we expand on this below.

First, we want to call attention to how our investigation sheds light on an inherent contradiction in the ES valuation discourse. $\mathrm{RV}$ is intended to better describe how people actually think and behave and this is fused with the question of why we should protect nature. Maier and Feest (2016) point out how the authors of the IPBES framework (i.e. Díaz et al. 2015) conflate the two separate questions of describing and assessing how people value nature versus normative and prescriptive questions of values of nature. As we have shown above with the contrast between ES valuation and environmental ethics, these two questions requires very different kinds of investigation. That is, describing how people value nature, regardless of how accurate the methods are, does not necessarily provide us with answers to the underlying moral concerns. Another justification of RV is that it is seen as a better representation of people's worldviews and motivations. This idea seems to align with the perspective that philosophers have been asking the wrong questions with regards to what motivates people to act for biodiversity conservation (c.f. Odenbaugh 2016). While the concern of motivating people is highly warranted, our overview demonstrates that the aim of ethics is not to accurately describe either how people value nature or how they are best motivated. A closer reading of disciplinary perspectives and engagement with theoretical underpinnings can prevent such confusion from the outset. That is not to say that disciplinary questions of values should be kept separate, or that disciplinary boundaries should not be challenged. RV can have significant potential in the quest to integrate perspectives on the why, what and how of values of nature that can underpin sustainability transitions.

We also want to stress that conflation of descriptive and normative values here implies a risk of overriding moral considerations of nature if these become subject to be reconceptualization as descriptive values with the application of RV. With RV being developed as a strategy to inform IPBES assessments (Chan et al. 2018), diverse perspectives from across the social sciences and humanities are increasingly re-positioned and conceptualized according to those theoretical premises (Pascual et al. 2018). This includes adapting to how the NCP as a conceptual framework, just like ES, is one-directional and not able to reflect intrinsic value, if intrinsic value is conceived of as independent of humans (Kenter 2018). For example, the act of caring for nature, or an ethics of care (Jax et al. 2019), here becomes interpreted as either intrinsic value being something unrelated to human-nature values relationships, or as a matter of 'contribution' to wellbeing. RV thereby deliberately manifests the separation of intrinsic value from the scope of NCP or ES, and as Piccolo (2017) points out, posits people's subjective relations as the locus of interest, and as separate from nature.

$\mathrm{RV}$ has often been presented as a third category next to intrinsic and instrumental value, but the concept does not seem to contribute to solving problems within environmental ethics. Instead, RV as a values concept, as it has been described in the recent literature, is aimed at solving problems that arise as a consequence of the theoretical foundations of ES and ES valuation. The problem seems to lie in how the axiological categories of intrinsic versus instrumental value are defined and operationalized within the ES paradigm. As demonstrated above, ES valuation and $\mathrm{RV}$ conceptualization formulate intrinsic value in terms of objective value, and instrumental value is described as based on preference satisfaction. $\mathrm{RV}$ is an effort to overcome the dichotomy of values in values assessments where intrinsic value is represented by conservationists and instrumental value associated with economics, through including 'noninstrumental anthropocentric' values seen as represented by perspectives from the social sciences and humanities.

$\mathrm{RV}$ is thus more than a values concept, since it also is used as a rationale for broadening the otherwise mostly positivist or post-positivist epistemological perspective within ES valuation and ES-related approaches, to include more of the qualitative social sciences, humanities and in general more constructivist epistemologies and relativist research traditions. The "novel" focus on relations and meaning through qualitative and interpretivist methodology is old territory to many fields that traditionally have fallen outside of ES valuation. RV, however, is developed as an expansion of the ES concept, which is rooted in realist traditions and this history seems to be part of the reason behind the apparent theoretical identity crisis and lack of philosophical perspective that the RV concept is suffering from. Kenter et al. (2019) describe how social values and relational values have both evolved from a recognition of the limitations 
of mainstream economic valuation within ES assessments which opened up a field initially associated with cultural ES that has relied on wide ranging methods but with little clarification of underpinning theoretical perspectives. The aim of the RV concept thus can better be described as an attempt at establishing a new field with its own methodological and epistemological basis rather than adding a theoretical value concept. Our point here is that RV has to do with a shift towards or explicit engagement with more qualitative methodologies, and that it can be questioned if studies that are now applying the concept can be seen as employing a more constructivist perspective or qualitative methodology, which includes a more comprehensive idea of culture than ES, rather than a new type of value.

The idea of seeing RV as a 'boundary object' (Star and Griesemer 1989) that could be used to integrate specific epistemological perspectives on value is perhaps helpful here. Boundary objects are flexible enough to adapt to the needs of separate and different epistemic communities whilst being sufficiently rigid to allow for effective communication. When applied to concepts such as RV, however, questions arise as to what it is about this concept, beyond the appeal that the label itself might have, that can ensure communication. ${ }^{4}$ The mere sharing of a term is presumably not sufficient to adequately integrate perspectives from the qualitative social sciences and humanities into ES valuation. Fundamental ontological and epistemological inconsistencies can be expected between how these disciplines conceive of nature and culture versus how these have been conceptualized in ES valuation (c.f. Stålhammar and Pedersen 2017; Kirchhoff 2019). RV has nonetheless (already) contributed to an expansion of disciplinary perspectives in ES valuation, and now provides an opportunity for further cross-fertilization of perspectives.

Moreover, our examples of different interpretations of RV in environmental psychology shows how it is important to consider the level of how the concept can be operationalized on a spectrum from ontological meanings of the term to epistemological and methodological. This relies on the question of whether this concept calls for a re-evaluation of the very premises of how to think about human-nature relationships, crucially including a call to go beyond "Cartesian dualisms' to shift the focus from subject-object as the locus of interest to that of relationships (e.g., Muraca 2011). However, perspectives that align with e.g., a 'nondualist' monist mind-world perspective (Jackson 2010) do not necessarily align with some of the accounts of RV that we have described here, such as Klain et al. (2017), which raises questions of the operationalization of ontological

\footnotetext{
${ }^{4}$ See Thorén (2014) for a discussion-targeting the concept (resilience)—of boundary objects that highlights this point.
}

interpretations of RV. Nonetheless, efforts to operationalizing and apply RV should make explicit what aspect of the concept, on what theoretical 'level', as well as what discipline/field is drawn upon. This special issue provides useful distinctions and overviews (see Rawluk et al. 2019 this issue and Kenter et al. 2019).

Even though our analysis points to a lack of utility of RV as a values category, we welcome RV as an interdisciplinary object or epistemological framing. The concepts importance for the sustainability agenda can be considerable in the long term, despite that it might not force different disciplines together under perfect conditions.

Acknowledgements Open access funding provided by Lund University. We thank two anonymous reviewers for some very helpful and constructive comments on an earlier version of this paper. This paper was written within the LUCID project funded by The Swedish Research Council Formas (Linneus Centre LUCID; grant 259-2008-1718).

Open Access This article is distributed under the terms of the Creative Commons Attribution 4.0 International License (http://creativeco mmons.org/licenses/by/4.0/), which permits unrestricted use, distribution, and reproduction in any medium, provided you give appropriate credit to the original author(s) and the source, provide a link to the Creative Commons license, and indicate if changes were made.

\section{References}

Altman I, Low SM (1992) Place attachment. Plenum Press, New York Altman I, Rogoff B (1991) World views in psychology; trait, interactional, organismic, and transactional perspectives. In: Stokols D, Altman I (eds) Handbook of environmental psychology, vol 1. Wiley, Malabar, pp 7-40

Arias-Arévalo P, Martín-López B, Gómez-Baggethun E (2017) Exploring intrinsic, instrumental, and relational values for sustainable management of social-ecological systems. Ecol Soc 22(4):43

Arias-Arévalo P, Gómez-Baggethun E, Martín-López B, Pérez-Rincón M (2018) Widening the evaluative space for ecosystem services: a taxonomy of plural values and valuation methods. Environ Values 27(1):29-53

Boulding KE (1966) The economics of the coming spaceship Earth. In: Daly HE (ed) Environmental quality issues in a growing economy. Johns Hopkins University Press, Baltimore

Braat Leon C (2018) Five reasons why the Science publication "Assessing nature's contributions to people" (Diaz et al. 2018) would not have been accepted in ecosystem services. Ecosyst Serv 30:A1-A2

Brennan A, Lo Y (2016) "Environmental ethics", the stanford encyclopedia of philosophy (winter 2016 edition). In: Edward NZ (ed). https://plato.stanford.edu/archives/win2016/entries/ethics-envir onmental/

Brown T (1984) The concept of value in resource allocation. Land Econ 60(3):231

Bryce R, Irvine KN, Church A, Fish R, Ranger S, Kenter JO (2016) Subjective well-being indicators for large-scale assessment of cultural ecosystem services. Ecosyst Serv 21:258-269

Carson R (1962) Silent spring. Houghton Mifflin, Boston

Chan KM, Satterfield T, Goldstein J (2012) Rethinking ecosystem services to better address and navigate cultural values. Ecol Econ $74: 8-18$ 
Chan KM, Balvanera P, Benessaiah K, Chapman M, Díaz S, GómezBaggethun E, Luck GW (2016) Opinion: why protect nature? Rethinking values and the environment. Proc Natl Acad Sci 113(6):1462-1465

Chan KMA, Gould RK, Pascual U (2018) Editorial overview: Relational values: what are they, and what's the fuss about. Curr Opin Environ Sustain 35:A1-A7

Costanza R, De Groot R, Sutton P, Van Der Ploeg S, Anderson SJ, Kubiszewski I, Farber S, Turner RK (2014) Changes in the global value of ecosystem services. Glob Enviro Change 26:152-158

Daily CG, Polasky S, Goldstein J, Kareiva PM, Mooney HA, Pejchcar L, Ricketts TH, Salzman J, Shallenberg R (2009) Ecosystem services in decision making: time to deliver. Front Ecol Environ $7: 21-28$

de Groot R, Alkemade R, Braat L, Hein L, Willemen L (2010) Challenges in integrating the concept of ecosystem services and values in landscape planning, management and decision making. Ecol Complex 7:260-272

de Groot R, Brander L, van der Ploeg S, Costanza R, Bernard F, Braat L, Christie M, Crossman N, Ghermandi A, Hein L, Hussain S, Kumar P, McVittie A, Portela R, Rodriguez LC, ten Brink P, van Beukering P (2012) Global estimates of the value of ecosystems and their services in monetary units. Ecosyst Serv 1:50-61

Devall B (1988) Simple in means, rich in ends: Practicing deep ecology. Gibbs M. Smith, Salt Lake City

Díaz S, Demissew S, Carabias J, Joly C, Lonsdale M, Ash N, Bartuska A (2015) The IPBES conceptual framework-connecting nature and people. Curr Opin Environ Sustain 14:1-16

Díaz S, Pascual U, Stenseke M, Martín-López B, Watson RT, Molnár Z, Hill R, Chan KMA, Baste IA, Brauman KA et al (2018) Assessing nature's contributions to people. Science 359(6373):270-272

Dunlap RE, Van Liere KD, Mertig AG, Jones RE (2000) Measuring endorsement of the new ecological paradigm: a revised NEP scale. J Soc Issues 56(3):425-442

Ehrlich PR (1968) The population bomb. Ballantine Books, New York

Fish R, Church A, Winter M (2016) Conceptualising cultural ecosystem services: a novel framework for research and critical engagement. Ecosyst Serv 21:208-217

Fodor JA (1997) The representational theory of mind. Am Behav Sci 40(6):829-841

Fulton DC, Manfredo MJ, Lipscomb J (1996) Wildlife value orientations: a conceptual and measurement approach. Hum Dimens Wildl 1:24-47

Gifford R (2014) Environmental psychology matters. Annu Rev Psychol 65:541-579

Gómez-Baggethun E, Martín-López B (2015) Ecological economics perspectives on ecosystem services valuation. In: Martínez-Alier J, Muradian R (eds) Handbook of ecological economics. Edward Elgar Publishing, Cheltenham, pp 260-282

Gould R, Pai M, Chan K, Muraca B (2019) How one indigenous worldview informs relational values and social values. Sustainability science special feature: theoretical traditions of social values for sustainability. Sustain Sci

Hardin G (1968) The tragedy of the commons. Science 162(3859):1243-1248

Hejnowicz AP, Rudd MA (2017) The value landscape in ecosystem services: value, value wherefore art thou value? Sustainability 9:850

Hicks CC, Cinner JE, Stoeckl N, McClanahan TR (2015) Linking ecosystem services and human-values theory. Conserv Biol 29(5):1471-1480

Himes A, Muraca B (2018) Relational values: the key to pluralistic valuation of ecosystem services. Curr Opin Environ Sustain 35:1-7

Hirons M, Comberti C, Dunford R (2016) Valuing cultural ecosystem services. Annu Rev Environ Resour 41:545-574
Ingold T (2006) Rethinking the animate, re-animating thought. Ethnos J Anthropol 71(1):9-20

Ives C, Kendall D (2014) The role of social values in the management of ecological systems. J Environ Manage 144:67-72

Jackson PT (2010) The Conduct of Inquiry in International Relations: philosophy of science and its implications for the study of world politics. Routledge Press, London

Jax K, Barton DN, Chan KMA, de Groot R, Doyle U, Eser U, Görg C, Gómez-Baggethun E, Griewald Y, Haber W, Haines-Young R, Heink U, Jahn T, Joosten H, Kerschbaumer L, Korn H, Luck GW, Matzdorf B, Muraca B, Nebhöver C, Norton B, Ott K, Potschin M, Rauschmayer F, von Haaren C, Wichmann S (2013) Ecosystem services and ethics. Ecol Econ 93(C):260-268

Jax K, Calestani M, Chan KMA, Eser U, Keune H, Muraca B, O'Brien L, Potthast T, Voget-Kleshin L, Wittmer H (2019) Caring for nature matters: a relational approach for understanding nature's contributions to human well-being. Current Opin Environ Sustain 35:22-29

Justus J, Colyvan M, Regan H, Maguire L (2009) Buying into conservation: intrinsic versus instrumental value. Trends Ecol Evol 24(4):187-191. https://doi.org/10.1016/j.tree.2008.11.011

Kawall J (2017) A history of environmental ethics. In: Gardiner SMA, Thompson A (eds) 2016 Oxford handbook in environmental ethics. Oxford University Press, Oxford

Kenter JO (2016) Shared, plural and cultural values [special issue]. Ecosyst Serv 21(B): 175-372

Kenter JO (2018) IPBES: don't throw out the baby whilst keeping the bathwater; Put people's values central, not nature's contributions. Ecosyst Serv 33:40-43

Kenter JO, O'Brien L, Hockley N, Ravenscroft N, Fazey I, Irvine KN, Reed MS, Christie M, Brady E, Bryce R, Church A, Cooper N, Davies A, Evely A, Everard M, Fish R, Fisher JA, Jobstvogt N, Molloy C, Orchard-Webb J, Ranger S, Ryan M, Watson V, Williams S (2015) What are shared and social values of ecosystems? Ecol Econ 111:86-99

Kenter JO, Jobstvogt N, Watson V, Irvine KN, Christie M, Bryce $R$ (2016) The impact of information, value-deliberation and group-based decision-making on values for ecosystem services: integrating deliberative monetary valuation and storytelling. Ecosyst Serv 21:270-290

Kenter JO, Raymond C, Van Riper CJ, Azzopardi E, Brear MR, Calcagni F, Christie I, Christie M, Fordham A, Gould RK, Ives CD, Hejnowicz AP, Gunton R, Horcea-Milcu A, Kendal D, Kronenberg J, Massenberg JR, O'Connor S, Ravenscroft N, Rawluk A, Raymond IJ, Rodríguez-Morales J, Thankappan S (2019) Loving the mess: navigating diversity and conflict in social values for sustainability. Sustainability science special feature: theoretical traditions of social values for sustainability. Sustain Sci

Kirchhoff T (2012) Pivotal cultural values of nature cannot be integrated into the ecosystem services framework. Proc Natl Acad Sci 109:E3146

Kirchhoff T (2019) Abandoning the concept of cultural ecosystem services, or against natural-scientific imperialism. Bioscience 69(3):220-227

Klain SC, Olmsted P, Chan KMA, Satterfield T (2017) Relational values resonate broadly and differently than intrinsic or instrumental values, or the new ecological paradigm. PLoS One 12(8):1-21

Knez I, Ode Sang Å, Gunnarsson B, Hedblom M (2018) Wellbeing in urban greenery: the role of naturalness and place identity. Front Psychol 9:491

Kronenberg J, Andersson E (2019) Integrating social values with other value dimensions: parallel use vs. combination vs. full integration. Sustain Sci. https://doi.org/10.1007/s11625-019-00688-7 
Leopold A (1949) A sand county almanac, and sketches here and there. Oxford University Press, New York

Maes J, Crossman ND, Burkhard B (2016) Mapping ecosystem services. In: Potschin P, Haines-Young R, Fish R, Turner RK (eds) Routledge handbook of ecosystem services. Routlegde, London, pp 188-204

Maier DS, Feest A (2016) The IPBES conceptual framework: an unhelpful start. J Agric Environ Ethics 29(2):327-347

Marsh GP (1864) Man and nature. Charles Scribner, New York

Martin C, Czellar S (2016) The extended inclusion of nature in self scale. J Environ Psychol 47:181-194

Mayer FS, Frantz CM (2004) The connectedness to nature scale: a measure of individuals' feeling in community with nature. J Environ Psychol 24(4):503-515

Millennium Ecosystem Assessment (MEA) (2005) Ecosystems and human well- being: synthesis. Island Press, Washington, DC

Moore GE (1922) The conception of intrinsic value. Philos Stud 260

Muraca B (2011) The map of moral significance: a new axiological matrix for environmental ethics. Environ Values 20(3):375-396

Muraca B (2016) Relational values: a whiteheadian alternative for environmental philosophy and global environmental justice. Balkan J Philos 8(1):19-38

Næss A (1973) The shallow and the deep, long-range ecology movement: a summary. Inquiry 16(1-4):95-100

Næss A (1989) Ecology, community and lifestyle (D. Rothenberg, Trans). Cambridge University Press, Cambridge

O'Connor S, Kenter JO (2018) Making intrinsic values work; a communicative approach to integrating intrinsic values of non-human nature with ecosystem services. Sustainability science special feature: theoretical traditions of social values for sustainability. Sustain Sci

Odenbaugh J (2016) Protecting biodiversity and moral psychology; or why philosophers are asking the wrong questions. In: Garson J, Plutynski A, Sarkar S (eds) The routledge handbook of philosophy of biodiversity. Routledge, London

O'Neill J, Light A, Holland A (2008) Environmental values. Routledge, New York

O'Neill J (1992) The varieties of intrinsic value. Monist 75(2):119-137

Pascual U, Balvanera P, Díaz S, Pataki G, Roth E, Stenseke M, Watson RT, Başak Dessane E, Islar M, Kelemen E et al (2017) Valuing nature's contributions to people: the IPBES approach. Curr Opin Environ Sustain 26-27:7-16

Pascual U, Gould R, Chan KMA (2018) Sustainability challenges: relational values [special issue]. Curr Opin Environ Sustain 35:1-132

Piccolo JJ (2017) Intrinsic values in nature: objective good or simply half of an unhelpful dichotomy? J Nat Conserv 37:8-11

Pojman L (2012) How should we live? An introduction to ethics. Wadsworth, Cengage learning

Rawluk A, Ford R, Anderson N, Williams (2018) Exploring multiple dimensions of values and valuing: a conceptual framework for mapping and translating values for social ecological research and practice. Theoretical traditions in social values for sustainability. Sustain Sci. https://doi.org/10.1007/s11625-018-0639-1

Raymond CM, Kenter JO (2016) Transcendental values and the valuation and management of ecosystem services. Ecosyst Serv 21(Part B):241-257

Rokeach M (1973) The nature of human values. Free Press, New York Sagoff M (1994) Should preferences count? Land Econ 70(2):127-144

Schmidtz D (2015) Value in Nature. In: Hirose I, Olson J (eds) The oxford handbook of value theory. Oxford University Press, New York, pp 381-399

Scholte S, van Teeffelen AJ, Verburg PH (2015) Integrating sociocultural perspectives into ecosystem service valuation: a review of concepts and methods. Ecol Econ 114:67-78

Scholte SS, Todorova M, van Teeffelen AJ, Verburg PH (2016) Public support for wetland restoration: what is the link with ecosystem service values? Wetlands 36(3):467-481
Schroeder H (2013) Sensing value in place. In: Ewert AE (ed) Placebased conservation. Springer, Dordrecht, pp 73-87

Schultz PW (2001) The structure of environmental concern: concern for self, other people, and the biosphere. J Environ Psychol 21(4):327-339

Schulz C, Martin-Ortega J (2018) Quantifying relational values: why not? Curr Opin Environ Sustain 35:15-21

Schwartz SH (1992) Universals in the content and structure of values: theoretical advances 796 and empirical tests in 20 countries. Adv Exp Soc Psychol 25:1-65

Schwartz SH (2012) An overview of the Schwartz theory of basic values. Online Read Psychol Cult 2(1):1. https://doi. org/10.9707/2307-0919.1116

Schwartz SH, Bilsky W (1987) Toward a universal psychological structure of human values. J Pers Soc Psychol 53:550-562

Shmelev ES (2012) Ecological economics: sustainability in practice. Springer Science + Business Media B.V., Berlin

Silvertown J (2015) Have ecosystem services been oversold? Trends Ecol Evol 30:641-648

Small N, Munday M, Durance I (2017) The challenge of valuing ecosystem services that have no material benefits. Glob Environ Change 44:57-67

Stålhammar S, Pedersen E (2017) Recreational cultural ecosystem services: how do people describe the value? Ecosyst Serv 26:1-9

Star SL, Griesemer JR (1989) Institutional ecology, translations' and boundary objects: amateurs and professionals in Berkeley's Museum of Vertebrate Zoology, 1907-39. Soc Stud Sci 19(3):387-420

Stern PC (2000) New environmental theories: toward a coherent theory of environmentally significant behavior. J Soc Issues 56(3):407-424

Stern PC, Dietz T (1994) The value basis of environmental concern. J Soc Issues 50(3):65-84

Stern PC, Dietz T, Kalof L (1993) Value orientations, gender, and environmental concern. Environ Behav 25(5):322-348

Tadaki M, Sinner J, Chan KMA (2017) Making sense of environmental values: a typology of concepts. Ecol Soc 22(1):7

TEEB (2010) The economics of ecosystems and biodiversity: ecological and economic foundations. In: Kumar P (ed). Earthscan. London

Thorén H (2014) Resilience as a unifying concept. Int Stud Philos Sci 28(3):303-324

Venkatachalam L (2007) Environmental economics and ecological economics: where they can converge? Ecol Econ 61:550-558

Von Humboldt A (1850) A view of nature. Henry G. Bohn, London

Walz A, Schmidt K, Ruiz-Frau A, Nicholas KA, Bierry A, de Vries Lentsch A, Dyankov A, Joyce D, Liski A, Marba N, Rosário IT, Scholte SSK (2019) Sociocultural valuation of ecosystem services for operational ecosystem managment: mapping applications by decision contexts in Europe. Reg Environ Change (2019). https:// doi.org/10.1007/s10113-019-01506-7

Werner CM, Altman I (2000) Humans and nature: insights from a transactional view. In: Wapner $\mathrm{S}$ et al (eds) Theoretical perspectives in environment-behavior research. Kluwer Academic, New York, pp 21-37

White L (1967) The historical roots of our ecologic crisis. Science 155(3767):1203-1207

Publisher's Note Springer Nature remains neutral with regard to jurisdictional claims in published maps and institutional affiliations. 